\title{
An ecological study for Sri Lanka about health effects of coconut
}

\author{
L K Athauda, A R Wickremasinghe, B Kumarendran, A Kasturiratne
}

(Index words: coconut consumption, cardiovascular mortality, Sri Lanka)

\begin{abstract}
An ecological correlation study was conducted to determine the association between consumption of coconut products and cardiovascular disease (CVD) deaths in Sri Lanka. Data on coconut consumption patterns from 1961 to 2006 were abstracted from the FAO database, and mortality data from reports of the Department of Census and Statistics, and UN databases. Correlational and regression analyses were carried out. There was no increase in the per capita consumption of coconut products from 1961 to 2006 (range 54.1-76.2kg/ capita/year). The CVD death rates and the proportionate mortality rate due to CVD increased from 1961 to 2006. CVD death rates were significantly associated with per capita GDP, percentage of urban population, and elderly dependency ratio but not consumption of coconut products after adjusting for the other variables $\left(R^{2}=0.94\right)$. The results do not provide evidence at the population level that consumption of coconut products increases mortality due to cardiovascular diseases.
\end{abstract}

Ceylon Medical Journal 2015; 60: 97-99

\section{Introduction}

Evidence of adverse cardiovascular effects of coconut has been provided by human studies which correlated saturated fat consumption with coronary heart disease [1,2]. Recent epidemiological studies do not provide evidence of an association between dietary saturated fat and morbidity and mortality due to cardiovascular diseases [3]. Contrary to popular belief, many population based studies have shown that cardiovascular diseases and consumption of coconut is negatively correlated $[4,5]$. Studies explain that neither an excessive total fat intake, nor an increase in the total and LDL cholesterol levels, could fully explain the increased vulnerability to cardiovascular disease in the Sri Lankan population [6]. It has been reported that despite the high consumption of coconut as saturated fats, the ratios of total cholesterol to HDL-cholesterol, and LDL-cholesterol to HDL-cholesterol were lower, thus lowering cardiovascular disease (CVD) risk in rural males with a high degree of physical activity, subsisting on a diet consisting mainly of plant food [7].

Given these conflicting evidence and that coconut and its products are an important constituent of the Sri Lankan diet, we conducted this study to determine the association between consumption of coconut products and CVD death rates at the population level.

\section{Methods}

Data from 1961 to 2006 were abstracted from different sources; coconut consumption data from the Food and Agricultural Organization database, population data and cigarette production figures from the United Nations database. Cardiovascular disease deaths from reports of the Department of Census and Statistics, Sri Lanka and per capita Gross Domestic Product (GDP) from the World Bank database. All diseases of the circulatory system were amalgamated from the International Classification of Disease (ICD) versions 8, 9 and 10. The list of diseases included, acute and chronic rheumatic fever, hypertensive disease, ischaemic heart disease (IHD), pulmonary heart disease and pulmonary circulatory disease, cerebrovascular disease, disease of arteries and veins, and other forms of heart disease.

The percentage urban population was defined as the percentage of the population living in municipal council and urban council areas of Sri Lanka [8]. The elderly dependency ratio was defined as the ratio between the population over 65 years, and the population between $15-65$ years of age [9]. Correlation and regression analyses were carried out using SPSS Version 20.

\section{Results}

From 1961 to 2006, the average consumption of coconut including copra and oil was $66.19 \mathrm{~kg} /$ capita/year, the average energy supply from all coconut products was $271.47 \mathrm{kcal} / \mathrm{capita} /$ day, and the average fat supply from all coconut products was $24.46 \mathrm{~g} /$ capita/day. The death rate due to all causes has declined from 1961 to 2006 while the

Department of Public Health, Faculty of Medicine, University of Kelaniya, Sri Lanka.

Correspondence: LKA, e-mail: <lathika.athauda@gmail.com>. Received 12 February and revised version accepted 14 March 2015. 
CVD death rates have increased from 96 to 146 per 100,000 population (Figure). Consumption patterns of both coconut and coconut oil have remained unchanged from 1961 to 2006. Consumption of coconut ( $p=0.038$ ) and coconut oil (0.059) was negatively correlated with CVD deaths rates (Table 1). The per capita GDP, elderly dependency ratio and per capita cigarette consumption (with a lag of 25 years) were significantly correlated with CVD deaths rates (Table 1).

In multiple linear regression analyses, per capita GDP, percentage of urban population and the elderly dependency ratio were significant predictors of CVD death rates after controlling for consumption of coconut and coconut oil, and life expectancy at birth (Table 2). When per capita consumption of cigarettes with a lag of 25 years was included in the model, none of the variables were significant predictors probably due to the small number of data points $(n=20)$ (data not shown).

\section{Discussion}

Consumption patterns of coconut and coconut products have remained unchanged in Sri Lanka from 1961

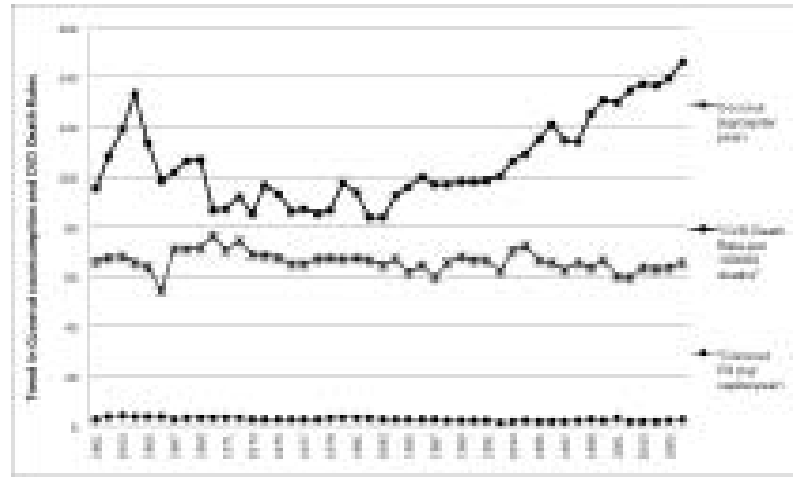

Figure. Trends of coconut and coconut oil consumption and cardiovascular death rates in Sri Lanka 1961-2006 to 2006. CVD death rates and the proportionate mortality rate due to CVDs have increased though the death rate due to all causes has decreased during this period. Per capita GDP, percent urban population and the elderly dependency ratio were significant predictors of CVD death rates after controlling for consumption of coconut and coconut oil, and life expectancy at birth.

Surprisingly, the percentage of urban population was negatively associated with cardiovascular mortality. This may be due to availability of better and more advanced health care services in urban centers as compared to rural areas. This highlights the multifactorial nature of cardiovascular diseases and the interplay of many factors in its causation.

Coconut has been an integral part of the Sri Lankan and South Indian diets. Our results indicate that per capita consumption patterns of coconut oil and coconut have not changed from 1961-2005. Although this fact alone suggests no marked change in traditional dietary patterns, it is possible that preparations and ways of consuming coconut, that impact on its health effects, may have changed over time. Given the benefits of coconut in health

Table 1. Correlations between CVD death rates and selected variables

\begin{tabular}{ll}
\hline Variable & $\begin{array}{l}\text { Correlation } \\
\text { coefficient }(p \text { value })\end{array}$ \\
\hline Consumption of coconut products & $-0.307(p=0.038)$ \\
Consumption of coconut oil & $-0.281(p=0.059)$ \\
Per capita GDP & $0.583(p<0.001)$ \\
Percentage urban population & $0.212(p=0.157)$ \\
Elderly dependency ratio & $0.746(p<0.001)$ \\
Life expectancy & $-0.084(p=0.577)$ \\
$\begin{array}{l}\text { Per capita cigarette consumption } \\
\text { (lag of 25 years) }\end{array}$ & $0.944(p<0.001)$ \\
\hline
\end{tabular}

Table 2. Results of regression analysis using CVD death rates (per 100,000 population) as the dependent variable

\begin{tabular}{|c|c|c|c|c|}
\hline Variable & $\begin{array}{l}\text { Regression } \\
\text { coefficient }\end{array}$ & $\begin{array}{l}\text { Standard error of } \\
\text { regression coefficient }\end{array}$ & $p$ value & $\begin{array}{l}\text { 95\% confidence interval } \\
\text { of regression coefficient }\end{array}$ \\
\hline Constant & 475.073 & 79.156 & & \\
\hline Per capita coconut consumption & 0.325 & 0.308 & 0.299 & $-0.299-0.949$ \\
\hline Per capita coconut oil consumption & 2.970 & 2.415 & 0.226 & $-1.915-7.854$ \\
\hline Per capita GDP & 0.040 & 0.009 & $<0.001$ & $0.022-0.059$ \\
\hline \% urban population & -16.129 & 3.725 & $<0.001$ & $-23.663-(-8.596)$ \\
\hline Elderly Dependency Ratio & -13.511 & 4.833 & 0.008 & $-23.286-(-3.736)$ \\
\hline Life expectancy & -0.337 & 0.612 & 0.585 & $-1.575-0.901$ \\
\hline
\end{tabular}

$R^{2}=0.940(n=45)$ 
promotion and disease prevention, it is heartening to note that consumption patterns have not changed over time [10].

Based on the results of this study, the rise in cardiac morbidity and mortality over the years is unlikely to be due to consumption of coconuts; factors other than coconut consumption were predictors of cardiovascular mortality. Hence the belief that coconut increases risk of cardiovascular disease needs to be revisited.

\section{Acknowledgments}

We acknowledge the management and the research team of the Coconut Research Institute (CRI) for initiating this research project. We also thank Dr. Asoka Dissanayake and Dr. Palitha Abeykoon for their valuable comments on the manuscript. We acknowledge the research funds provided by the Coconut Research Institute, Lunuwila, Sri Lanka for this study.

\section{Conflicts of interests}

There are no conflicts of interest.

\section{References}

1. Kato H, Tillotson J, Nichaman M Z, et al. Epidemiological studies of coronary heath disease and storke in Japanese men living in Japan, Hawai and California. Am J Epidemiol 1973; 97: 372-85.

2. Keys A, Aravanis C, Blackburn H W, et al. Epidemiological studies related to coronary heart disease: characteristics of men aged 40-59 years in seven countries. Acta Med Scand Suppl 1966; 460: 1-392.

3. Ascherio A, Rimm EB, Giovan nucci EL, et al. Dietary fat and risk of coronary heart disease in men: cohort follow up study in the United States. BMJ 1996: 313; 84-90.

4. Conrado SD. Coconut oil: Atherogenic or not? (What therefore causes atherosclerosis?). Philipp J Cardiol 2003; 31: $97-104$.

5. Proir IA, Davidson F, Salmond CE, Czochanska Z. Cholesterol, coconuts, and diet on Polynesian atolls: a natural experiment: the Pukapuka and Tokelau island studies. Am J Clin Nutr 1981; 34: 1552-61.

6. Abeywardena MY, Dietary fats, carbohydrates and vascular disease: Sri Lankan perspectives. Atherosclerosis 2003; 171: 157-61.

7. Atukorala TM, Jayawardene MI. Lipid patterns and dietary habits of healthy subjects living in urban, suburban and rural areas. Ceylon Med J 1991; 36: 9-16.

8. Ministry of Health Annual Bulletin Sri Lanka 2007, Medical Statistics Unit, Ministry of Health, Sri Lanka, 2007.

9. United Nations database for population data accessed in March 2012, available at http://data.un.org/Data.aspx? $\mathrm{q}=$ population\&d=PopDiv\&f=variableID\%3a12

10. DebMandal M, Mandal S. Coconut (Cocus Nucifera L. Arecaceae): In health promotion and disease prevention. Asian Pacific Journal of Tropical Medicine 2011; 241-7. 